University of Nebraska - Lincoln

DigitalCommons@University of Nebraska - Lincoln

2008

\title{
Host and vector movement affects genetic diversity and spatial structure of Buggy Creek virus (Togaviridae)
}

Charles R. Brown

University of Tulsa, charles-brown@utulsa.edu

Mary Bomberger Brown

University of Tulsa, mbrown9@unl.edu

Abinash Padhi

University of Tulsa

Jerome E. Foster

University of Tulsa

Amy T. Moore

University of Tulsa, amy-moore@utulsa.edu

See next page for additional authors

Follow this and additional works at: https://digitalcommons.unl.edu/publichealthresources

Part of the Public Health Commons

Brown, Charles R.; Brown, Mary Bomberger; Padhi, Abinash; Foster, Jerome E.; Moore, Amy T.; Pfeffer, Martin; and Komar, Nicholas, "Host and vector movement affects genetic diversity and spatial structure of Buggy Creek virus (Togaviridae)" (2008). Public Health Resources. 239.

https://digitalcommons.unl.edu/publichealthresources/239

This Article is brought to you for free and open access by the Public Health Resources at DigitalCommons@University of Nebraska - Lincoln. It has been accepted for inclusion in Public Health Resources by an authorized administrator of DigitalCommons@University of Nebraska - Lincoln. 


\section{Authors}

Charles R. Brown, Mary Bomberger Brown, Abinash Padhi, Jerome E. Foster, Amy T. Moore, Martin Pfeffer, and Nicholas Komar 


\title{
Host and vector movement affects genetic diversity and spatial structure of Buggy Creek virus (Togaviridae)
}

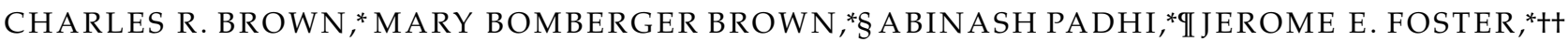 \\ AMY T. MOORE, ${ }^{*}$ MARTIN PFEFFER + and NICHOLAS KOMAR \\ *Department of Biological Sciences, University of Tulsa, Tulsa, OK 74104, USA, +Bundeswehr Institute of Microbiology, \\ Neuherbergstrasse 11, 80937 Munich, Germany, $\ddagger$ Division of Vector-Borne Infectious Diseases, Centers for Disease Control and \\ Prevention, PO Box 2087, Fort Collins, CO 80522, USA
}

\begin{abstract}
Determining the degree of genetic variability and spatial structure of arthropod-borne viruses (arboviruses) may help in identifying where strains that potentially cause epidemics or epizootics occur. Genetic diversity in arboviruses is assumed to reflect relative mobility of their vertebrate hosts (and invertebrate vectors), with highly mobile hosts such as birds leading to genetic similarity of viruses over large areas. There are no empirical studies that have directly related host or vector movement to virus genetic diversity and spatial structure. Using the entire E2 glycoprotein-coding region of 377 Buggy Creek virus isolates taken from cimicid swallow bugs (Oeciacus vicarius), the principal invertebrate vector for this virus, we show that genetic diversity between sampling sites could be predicted by the extent of movement by transient cliff swallows (Petrochelidon pyrrhonota) between nesting colonies where the virus and vectors occur. Pairwise $F_{\mathrm{ST}}$ values between colony sites declined significantly with increasing likelihood of a swallow moving between those sites per 2-day interval during the summer nesting season. Sites with more bird movement between them had virus more similar genetically than did pairs of sites with limited or no bird movement. For one virus lineage, Buggy Creek virus showed greater haplotype and nucleotide diversity at sites that had high probabilities of birds moving into or through them during the summer; these sites likely accumulated haplotypes by virtue of frequent virus introductions by birds. Cliff swallows probably move Buggy Creek virus by transporting infected bugs on their feet. The results provide the first empirical demonstration that genetic structure of an arbovirus is strongly associated with host/vector movement, and suggest caution in assuming that bird-dispersed arboviruses always have low genetic differentiation across different sites.
\end{abstract}

Keywords: alphavirus, arbovirus, bird movement, Buggy Creek virus, cliff swallow, genetic diversity, Oeciacus vicarius, Petrochelidon pyrrhonota, spatial structure, swallow bug

Received 8 December 2007; revision accepted 21 February 2008

Correspondence: Charles R. Brown, Fax: 918631 3944;

E-mail: charles-brown@utulsa.edu

$\S$ Present address: Tern and Plover Conservation Partnership, University of Nebraska, 3310 Holdrege St., Lincoln, NE 68583, USA. IIPresent address: Center for Infectious Disease Dynamics, Department of Biology, 208 Mueller Laboratory, The Pennsylvania State University, University Park, PA 16802, USA.

†+Present address: Department of Pre-clinical Sciences, Faculty of Medical Sciences, University of the West Indies, St. Augustine, Trinidad, West Indies.

\section{Introduction}

Knowing how arthropod-borne viruses (arboviruses) vary genetically in space can be critically important in identifying where strains that potentially impact people or wildlife may occur. Studies on a continental scale have suggested that some arboviruses are relatively genetically homogenous, such as eastern equine encephalomyelitis virus (EEEV; Weaver et al. 1993, 1994; Brault et al. 1999) and Highlands J virus (HJV; Cilnis et al. 1996) in eastern North America, western equine encephalomyelitis virus (WEEV) in western North America (Weaver et al. 1997), and Barmah 
Forest virus (Poidinger et al. 1997) and Sindbis virus (SINV) in Australia (Sammels et al. 1999). Others show greater genetic diversity, often with multiple strains or subtypes sometimes co-circulating in the same geographical area, such as EEEV in South America (Brault et al. 1999), dengue virus (Gould et al. 2001; Carrington et al. 2005) and Venezuelan equine encephalitis (Weaver et al. 2004) in Central and South America, Ross River virus in Australia (Lindsay et al. 1993), SINV in the Old World (Norder et al. 1996), and tick-borne encephalitis viruses throughout northern Eurasia (Zanotto et al. 1995).

Genetic diversity in arboviruses is generally thought to reflect dispersal and movement patterns of the typical enzootic reservoir host(s), with more sedentary hosts (such as small mammals) leading to greater virus diversity and spatial structure than more mobile hosts (such as birds) that presumably spread viruses over large geographical regions (Brault et al. 1999; Sammels et al. 1999; Gould et al. 2001). Movement of vectors can also potentially influence virus genetic structure (Tabachnick 1992; Merrill et al. 2005) although less emphasized to date, perhaps owing to the short lifespans and presumed reduced dispersal capabilities of small arthropods (Zanotto et al. 1995; Traore et al. 2005; cf. Sellers 1989).

Most of the evidence used to relate host or vector movement to genetic variability in viruses, however, is either indirect (e.g. estimates of migration in mosquito vectors using molecular data; Merrill et al. 2005), anecdotal (e.g. reports of migrant birds with active virus infections; Lord \& Calisher 1970; Calisher et al. 1971; Crans et al. 1994), or relies on assumptions based on broad-scale information about animal dispersal and movement patterns (e.g. Rappole \& Hubálek 2003; Reed et al. 2003). To our knowledge, no study has empirically measured host or vector movement over a given geographical area and related that movement to virus genetic diversity and spatial structure within that same area. By knowing how animal movement influences the prevalence of virus at a site (Brown et al. 2007) and the virus's genetic diversity, we can better predict spatial variation in infection rates or epizootic potential.

In this study, we examine how the extent of movement by vectors and a potential host affect genetic diversity and spatial structure of Buggy Creek virus (BCRV), an alphavirus in the WEEV complex (Hayes et al. 1977; Calisher et al. 1980 , 1988). By relating empirical measurements of animal movement to diversity of the E2 gene in the virus's envelope glycoprotein-coding region, we present evidence that the degree of spatial genetic variation in the virus within a relatively localized area is strongly correlated with the extent of local movement by vectors and hosts between sites. The E2 gene in alphaviruses codes for a glycoprotein that is responsible for cell receptor binding (e.g. Navaratnarajah \& Kuhn 2007) and is the region of the genome most sensitive to selection brought about by the immune systems of different hosts (Strauss \& Strauss 1994; Powers et al. 2001; Pfeffer et al. 2006). If there are functional differences among virus isolates that reflect varying levels of adaptation to cell receptors of different hosts, they are likely to be expressed in the E2 gene.

BCRV is a bird-associated alphavirus (Togaviridae) whose principal invertebrate vector is the blood-feeding swallow bug (Hemiptera: Cimicidae: Oeciacus vicarius), an ectoparasite of the colonially nesting cliff swallow (Petrochelidon pyrrhonota; Hopla et al. 1993; Brown et al. 2001, 2007). This virus is unusual in being one of the few known alphaviruses routinely vectored by an insect other than mosquitoes (Strauss \& Strauss 1994). The wingless swallow bugs are confined during much of the year to occupied and unoccupied cliff swallow nests at discrete colony sites (Loye 1985; Brown \& Brown 2004a, 2005), and thus the spatial foci for BCRV presence are predictable. This allows measurement of the virus's genetic diversity at sites of varying distances apart and the likelihood that swallows and the parasitic bugs move between those sites.

We estimated movement using mark-recapture of birds in the field and multistate statistical techniques. Multi-state mark-recapture models allow one to estimate the probability that a bird makes a transition from one geographical site (state) to another in the same statistical way that survival and recapture are typically estimated (Nichols \& Kendall 1995; Lebreton \& Pradel 2002). We explicitly focus on estimating within-season movement by cliff swallows (who carry bugs on their feet) because extensive mark-recapture data are available for this species in the study area, and from this, we infer potential movement by bug vectors. We do not consider movement of birds between years, because we have found no evidence that cliff swallows returning in early spring ever have measurable BCRV viremia upon arrival in the study area (V. O'Brien, A. Moore, K. Huyvaert, C. Brown, unpublished; see Hayes et al. 1977), and the birds do not carry bugs to their South American wintering grounds and back (Usinger 1966).

\section{Methods}

\section{Study organisms}

BCRV was first isolated in 1980 from swallow bugs collected at a cliff swallow colony along Buggy Creek in Grady County, west central Oklahoma (Hopla et al. 1993). BCRV and another alphavirus, Fort Morgan virus (FMV), which is also associated with cliff swallows and swallow bugs (Hayes et al. 1977; Calisher et al. 1980; Scott et al. 1984), are strains of the same virus (Pfeffer et al. 2006). There are two lineages of BCRV (A and B) that differ from each other by $>6 \%$ at the nucleotide level (Pfeffer et al. 2006).

Cliff swallows are highly colonial passerines that breed commonly in western North America from the Pacific coast 
to the Great Plains and more rarely farther east (Brown \& Brown 1995). They build gourd-shaped mud nests and attach them to the vertical faces of cliff walls, rock outcrops, or artificial sites such as the eaves of buildings or bridges. Their nests tend to be stacked closely together, often sharing walls. Cliff swallows are migratory, wintering in southern South America, and have a relatively short breeding season in North America. They begin to arrive at our study site in late April or early May and depart by late July. Most birds raise only one brood.

The haematophagous swallow bug is an ectoparasite primarily of cliff swallows. Swallow bugs are nest-based parasites that overwinter in the birds' nests or in the cracks and crevices of the nesting substrate near the nests. Infestations can reach 2600 bugs per nest, and when numerous, the bugs can reduce nestling and adult cliff swallow survival and affect colony-use patterns and dispersal by the birds (Brown \& Brown 1986, 1992, 1996, 2004b; Chapman \& George 1991; Loye \& Carroll 1991). Swallow bugs begin to reproduce as soon as they feed in the spring. Eggs are laid in several clutches that hatch over variable lengths of time, ranging from 3-5 days (Loye 1985) to 12-20 days (Myers 1928). Bug populations at an active colony site increase throughout the summer, reaching a peak at approximately the time nestling cliff swallows fledge. The bugs seem to be adapted to withstanding long periods of host absence, in some cases for up to three consecutive years (Smith \& Eads 1978; Loye 1985; Loye \& Carroll 1991; Rannala 1995). Bugs also parasitize introduced house sparrows (Passer domesticus) that occupy nests in cliff swallow colonies (Hopla et al. 1993; Brown et al. 2001). Swallow bugs disperse between nests within a colony by crawling on the substrate and can disperse between colony sites only by clinging to the feet and legs of cliff swallows that move from one site to another (Brown \& Brown 2004a).

\section{Study site}

Our study site is centred at the Cedar Point Biological Station $\left(41^{\circ} 13^{\prime} \mathrm{N}, 101^{\circ} 39^{\prime} \mathrm{W}\right)$ near Ogallala, in Keith County, along the North and South Platte Rivers, southwestern Nebraska, USA. Cliff swallows have been studied there since 1982. Approximately 170 cliff swallow colony sites are in our $200 \times 60-\mathrm{km}$ study area; about a third of these are not occupied by swallows in a given year. In our study area, colony size ranges from 2 to 6000 nests, with some birds nesting solitarily. Over a 25-year period, mean $( \pm \mathrm{SE})$ colony size $(n=1812)$ was $393( \pm 15)$ nests. Each colony site tends to be separated from the next nearest by 1-10 km but in a few cases by $\geq 20 \mathrm{~km}$. The study site is described in detail by Brown \& Brown (1996). Linear distances between sites were determined using global positioning system (GPS) coordinates taken in the field at each colony.

\section{Virus isolations and sequencing}

From a larger study of BCRV phylogenetics and ecology (Pfeffer et al. 2006; Brown et al. 2007; Moore et al. 2007), we used data from 19 swallow colony sites for which we had $\geq 8$ isolates of at least one of the BCRV lineages, collected from 1998 to 2006. The number of isolates per lineage per site varied from 8 to 40 , with a total of 377 used in this study. The colony sites sampled spanned a linear distance of $183 \mathrm{~km}$ from Morrill east to Lincoln counties, Nebraska (Fig. 1). All isolates were from swallow bugs collected mostly from the outsides of cliff swallow nests during the birds' summer nesting season (May-July); at one site, some isolates were from bugs collected behind the nests in winter (December). Virus was isolated from pools of 100 bugs. Details on field sampling and collecting are given in Moore et al. (2007) and Brown et al. (2007).

Bug pools were macerated by mortar and pestle and suspended in $1.0 \mathrm{~mL}$ of BA-1, a growth medium containing M-199 Hank's salts, 1\% bovine serum albumin, $0.05 \mathrm{M}$ Tris- $\mathrm{HCl}$ ( $\mathrm{pH} 7.5), 0.35 \mathrm{~g} / \mathrm{L}$ sodium bicarbonate, $100 \mathrm{U} / \mathrm{mL}$ penicillin, $100 \mu \mathrm{g} / \mathrm{mL}$ streptomycin, and $1 \mu \mathrm{g} / \mathrm{mL}$ Fungizone (Gibco-BRL). Homogenates were clarified by centrifugation. All isolates from 1998 to 2003 were identified by plaque assay on Vero cells and sequences performed on the first or second Vero passage (Pfeffer et al. 2006). Beginning in 2004, positive samples were first identified by reverse transcription-polymerase chain reaction (RT-PCR, Moore et al. 2007) and later confirmed with plaque assay. Some RT-PCR-positive samples from 2004 to 2006 that either did not plaque (see Moore et al. 2007), or were not tried on Vero cells, were sequenced directly from the RT-PCR product (see below). Because samples were not screened with RT-PCR before 2004, overall virus prevalence (of both lineages combined) at a given pair of colony sites was expressed as the percentage of total samples taken at those sites in 1998-2005 that were positive by plaque assay.

Viral RNA was extracted from $100 \mu \mathrm{L}$ of the infectious precleared supernatant of a Vero cell passage or from the bug homogenates using the QIAGEN QIAamp Mini Viral RNA extraction kit (QIAGEN). Five microlitres of the eluted RNA suspension was used as a template in an alphavirus RT-PCR to amplify the entire 1269 bp of the E2 gene, using a protocol modified from Pfeffer et al. (2006). The amplicon DNA, cleaned by Millipore Montage filter tubes using the manufacturer's protocol, was subjected to cycle sequencing using the ABI PRISM BigDye Terminator Cycle Sequencing Kit, version 3.1 (Applied Biosystems). In addition to the previously designed RT-PCR and sequencing primers (Pfeffer et al. 2006), we used additional primers in this study that are listed in Table 1.

Sequences were aligned against the corresponding region in a 1981 BCRV reference sequence (strain 81V1822, GenBank no. AF339474) and fragments combined for a 


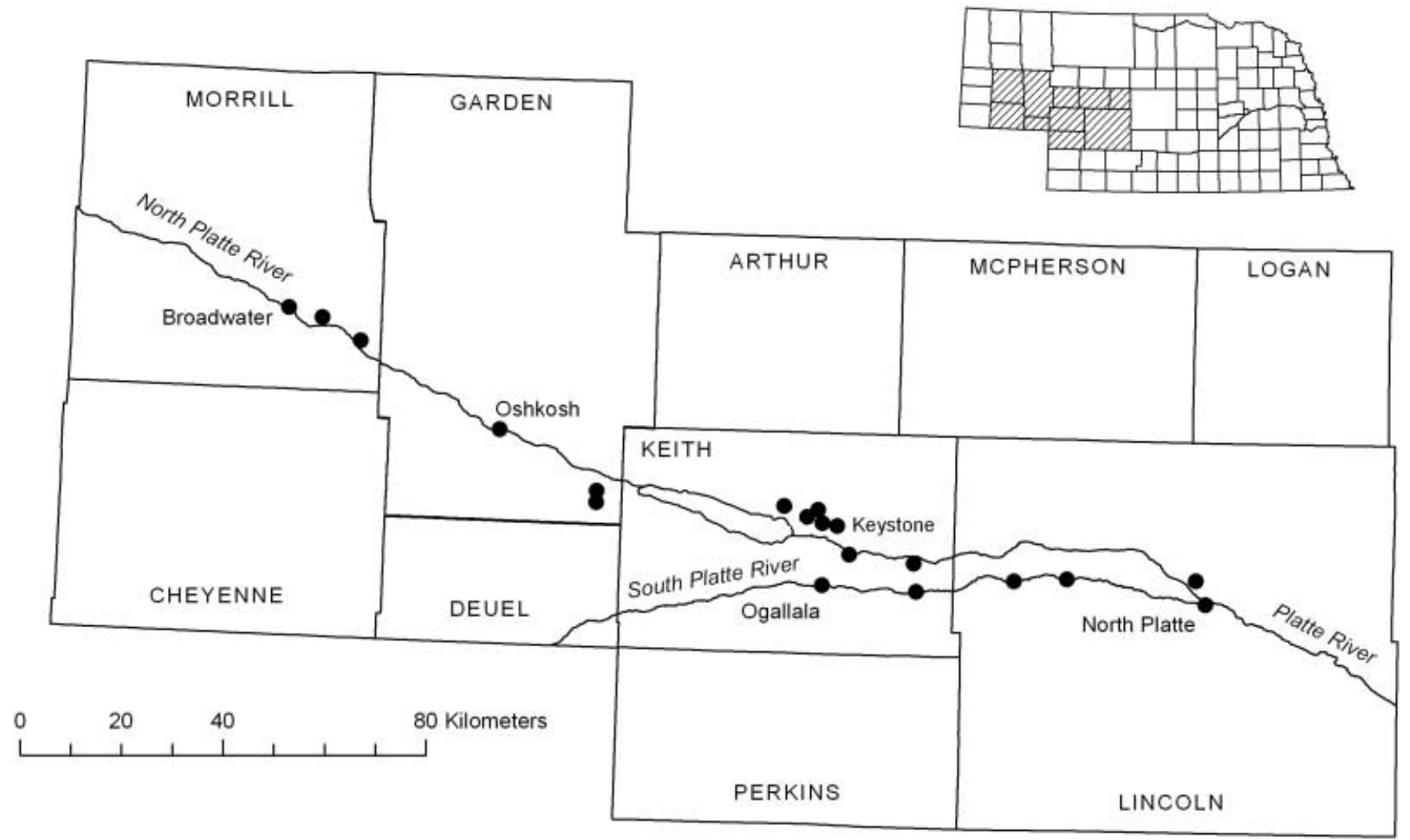

Fig. 1 Study area within southwestern Nebraska showing locations of 19 cliff swallow colony sites $(\bullet)$ sampled in this study. County names are given in upper case, with principal towns and rivers also shown.

Table 1 RT-PCR and sequencing primers used for BCRV. These primers were used in addition to those given in Pfeffer et al. (2006)

\begin{tabular}{ll}
\hline Primer name $^{*}$ & Sequence \\
\hline BCV2A1-F & TTGCAATACACGAGCGAGAA \\
BCV2A1-R & TTTCCCTTGTTGTTCTTCCAG \\
BCVE2A-F & CCTGGAAGAAAATGCCGATA \\
BCVE2A-R & CCCCAGTTTTCTGGTTGTCA \\
1442-R & ATGTATCCGGCACTCGACT \\
BCVE2B-F & GAGTCGAGTGCCGGATACAT \\
BCVE2B-R & CCCAAAGGAAGGCTGATTA \\
1806-F & AGGCATCACTTTACACCTCAC \\
\hline
\end{tabular}

${ }^{*}$ F indicates + direction; $\mathrm{R},-$ direction.

given isolate using SEQMAN 6.1 (DNAStar, LASERGENE) to obtain a contiguous nucleotide sequence for each sample. All sequences generated from this study are deposited in GenBank (accession nos EU483667-EU484043). The number of unique sequences at a site was determined using COLLAPSE version 1.2 (Posada 2004). Pairwise $F_{\mathrm{ST}}$ among sites for the two lineages was estimated by performing 10000 permutations using ARLEQUIN version 3.1 (Schneider et al. 2000). Sites with fewer than eight isolates of a given lineage were not included in the analyses. ARLEQUIN was also used to estimate the haplotype and nucleotide diversities of each lineage at each site. Each unique sequence that differed from all others by at least one nucleotide change was designated as a haplotype.

Each BCRV isolate is actually a sample of multiple and potentially variable virus particles within the host (Domingo 1998; Pfeffer et al. 2006); in our study, an isolate from a given sample represents the dominant genotype present. In three cases where an isolate had evidence of a sequence polymorphism, indicating the presence of multiple viral genotypes, it was excluded from analysis. Because of the genetic differences between the two BCRV lineages (Pfeffer et al. 2006), all analyses were carried out separately for the two lineages ( $\mathrm{A}$ and $\mathrm{B})$.

\section{Mist-netting and capture of birds}

In 1998-2006, we periodically mist-netted cliff swallows at colonies throughout the nesting season and used the resulting captures and recaptures to estimate daily movement probability. Nets were placed across culvert entrances and against the sides of bridges to catch birds as they exited their nests, or dropped from the top of a bridge to catch birds below as they flushed out (Brown 1998; 
Brown \& Brown 2004b). A capture occasion at a colony site equated to a single day, with netting usually carried out for 3-3.5 h per day per site. The occasions on which birds were caught extended over total time periods ranging from 3 to 82 days within the season at a given colony site (mean, 31.9). All birds caught received a numbered US Geological Survey band if not previously marked. Because both adult and juvenile cliff swallows move bugs between colonies (Brown \& Brown 1996) and both are potentially fed upon by bugs, for this study, we combined captures from adult birds and juveniles (those having fledged that season). Further details on field methods are given in Brown \& Brown (2004b) and Brown et al. (2007). All colony sites where we netted birds (24-33 per year) were used in the analyses in this study, either in estimating pairwise movement between specific sites or in estimating total movement into a colony site from all others (Brown et al. 2007).

\section{Statistical estimation of movement probability}

An encounter-history file for each marked bird was constructed for each year, containing all capture occasions during that summer pooled into consecutive 2-day intervals from the date netting started in the study area until it ceased. The encounter-history indicated whether each bird was caught during each 2-day interval and at which colony. Because of the large number of colonies in our study area at which birds were sampled and the resulting large number of potential movement parameters, for each year we restricted our estimation to the subset of the colonies where we had BCRV sequence data. Each of those sites was considered a separate state (sensu Lebreton \& Pradel 2002), and all other colonies (without sequence data) were combined into another state. This enabled us to estimate pairwise movement probabilities between specific colony sites. We did not have data for each pair of sites each year, because in some cases, either (i) one or both sites were unoccupied by cliff swallows, (ii) we did not net birds often enough ( $\geq 3$ times) at one or the other to estimate movement parameters, or (iii) one site was netted (because it became active) later in the year than the other, preventing the estimation of movement into the first site. To get overall movement between a pair of sites, we averaged the daily movement probabilities in each direction for that pair each season, and averaged the seasonal means for a pair. We assumed no movement between colony sites in any season when one or both was unoccupied by cliff swallows, and these years were excluded from the calculations for a given pair. Thus, an estimated movement probability of 0.0000 in a given year for a given pair was used only when that value was empirically estimated from recapture data.

In addition, to estimate overall movement into a site from all others in the study area, we did a two-state analysis (Brown et al. 2007). For this, we designated each capture as either present at the focal colony or present in any other colony in the study area (all combined into the same state). This allowed estimation of movement from all other colonies to the focal site in a given year; for analyses here, the yearly movement probabilities were averaged to get an overall estimate of movement into a given site in the years it was active. Further details on the two-state analyses are given in Brown et al. (2007).

Movement was measured by the parameter, $\psi( \pm 1 \mathrm{SE})$, which specifically describes the probability of an individual making the given transition between the specified sites (states) during any 2-day interval during the season. Movement in these analyses reflects both the daily travels of transient, nonbreeding birds between sites (perhaps while they are assessing where to nest) and the potential dispersal of breeding individuals elsewhere following a successful or unsuccessful nesting attempt.

In earlier analyses, we fit different multistate models to the data for representative colonies each year; these models and additional details on model fitting and goodness-of-fit can be found in Brown et al. (2007). Program MARK (White \& Burnham 1999) was used for model fitting and to generate maximum-likelihood estimates of survival, recapture, and movement probabilities. When the data sets did not meet the variance assumptions inherent in the binomial distribution used in mark-recapture analysis, we used quasilikelihood (Burnham \& Anderson 2002) to adjust the variance in movement probability estimates by calculating an overdispersion parameter, $\hat{\mathrm{c}}$, with the output from U-CARE's global multi-site test (Pradel et al. 2005; Brown et al. 2007).

For each colony, the best-fitting model used for maximum-likelihood parameter estimation modelled daily survival separately for each colony (state), usually varying with 'age' (to account for transients; Pradel et al. 1997); daily recapture probability varied with time (capture occasion) across the season; and daily movement between each pair of sites was time-constant across the nesting season but varied with each pair of sites. Our models necessarily reflected a balance between biological realism and computational limitations for the large number of parameters possible in the more complex multistate models. Because our models specifically estimated daily recapture probability, any differences among the 2-day intervals in the likelihood of re-catching a bird (due to sampling effort or number of sites netted) were accounted for in estimating movement probability.

\section{Results}

For BCRV lineage A, we had 17 pairs of colony sites where bi-daily bird movement between them could be empirically measured in one or more years, and for lineage $B$, we had 12 pairs. $F_{\mathrm{ST}}$ of BCRV isolates for a pair of sites significantly 


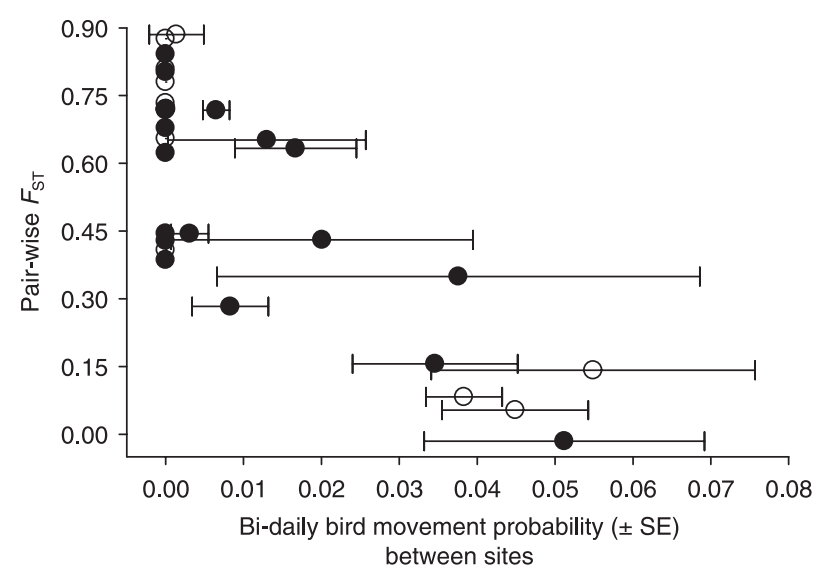

Fig. 2 Pairwise $F_{\mathrm{ST}}$ values for the $\mathrm{E} 2$ gene of $\mathrm{BCRV}$ in relation to the bi-daily bird movement probability, $\psi( \pm 1 \mathrm{SE})$, between each pair of cliff swallow colony sites. Movement was averaged over all years, 1998-2006, and in both directions for each pair. Lineage A is shown by closed circles $(\bullet)$ and lineage B by open circles $(O)$. $F_{\mathrm{ST}}$ declined significantly as movement probability increased $\left(r_{\mathrm{s}}=-0.66\right.$, $P=0.0001, n=29$, lineages combined).

decreased as the extent of bird movement between the sites increased; the same pattern held for both lineages (Fig. 2). Genetic similarity of BCRV was highest for pairs of sites with individual movement probabilities of $\geq 0.03$ (per 2-day interval) between them (Fig. 2). $F_{\mathrm{ST}}$ between sites varied significantly with bird movement probability when controlling for the effect of linear distance between the sites (partial correlation of $F_{\mathrm{ST}}$ and movement, $-0.74, P<0.0001$, $n=29)$. Both movement between sites $\left(F_{1,24}=10.4, P=0.004\right)$ and distance between sites $\left(F_{1,24}=11.5, P=0.003\right)$ explained a significant amount of the variation in pairwise $F_{\mathrm{ST}}$, but there was no significant effect of lineage type (A or B; $F_{1,24}=0.33, P=0.57$ ) or overall prevalence of $\mathrm{BCRV}$ at the sites $\left(F_{1,24}=3.6, P=0.07\right.$; ANCOVA $)$. There was no significant interaction between movement probability and distance in affecting $F_{\mathrm{ST}}\left(F_{1,24}=0.16, P=0.69\right)$.

We found a similar pattern when we restricted our analysis only to sites that had detectable bird movement between them (i.e. $\psi \neq 0.0000$ ). For these 14 pairs, $F_{\mathrm{ST}}$ between sites varied significantly with bird movement probability (partial correlation of $F_{\mathrm{ST}}$ and movement, $-0.81, P<0.0007$, $n=14$ ). In this case, only movement between sites $\left(F_{1,10}=10.5, P=0.010\right)$ explained a significant amount of the variation in pairwise $F_{\mathrm{ST}}$; there was no significant effect of distance between the sites $\left(F_{1,10}=0.28, P=0.61\right)$, lineage type $\left(F_{1,10}=0.42, P=0.53\right)$, or overall BCRV prevalence at the sites $\left(F_{1,10}=2.6, P=0.14\right.$; ANCOVA $)$.

All pairwise $F_{\mathrm{ST}}$ values were significant $(P \leq 0.02)$ except for two. These were for the two pairs of sites with the second $(0.0512 \pm 0.0180)$ and third $(0.0449 \pm 0.0094)$ highest estimated movement probabilities, and the lowest $(0.0150)$ and second lowest (0.0537) $F_{\mathrm{ST}}$ values, respectively (Fig. 2).
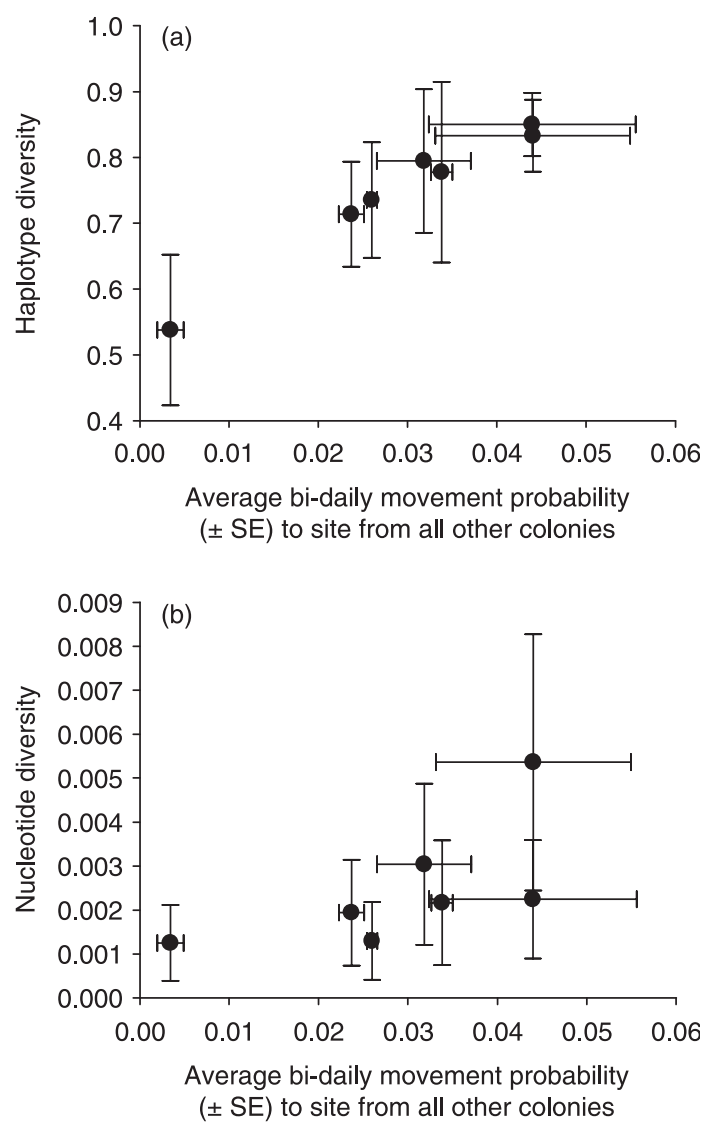

Fig. 3 Lineage A haplotype diversity ( $\pm 1 \mathrm{SE}$ ) (a) and nucleotide diversity ( \pm 1 SE) (b) of the E2 gene in BCRV at a cliff swallow colony site in relation to the bi-daily bird movement probability, $\psi$ ( \pm 1 SE), into that site from all others in the study area. Yearly movement probabilities into a site, as reported in Brown et al. (2007), were averaged across years at a site for this analysis. Haplotype diversity increased significantly with movement probability $\left(r_{\mathrm{s}}=0.93, P=0.007, n=7\right)$, as did nucleotide diversity $\left(r_{\mathrm{s}}=0.86, P=0.02, n=7\right)$.

For lineage A, both haplotype and nucleotide diversity of BCRV at a site increased significantly as the overall extent of bi-daily bird movement into a site (from all colonies) increased (Fig. 3). Thus, BCRV in bugs at sites that, on average, attracted more immigrant birds moving through them had higher levels of genetic variation (in the E2 gene) than did sites with less bird traffic. However, for lineage B, there was no significant effect of bird movement on either haplotype or nucleotide diversity (Fig. 4). Overall, nucleotide diversity was lower in lineage B than in lineage A (Figs 3 and 4).

\section{Discussion}

This study shows that the degree of genetic similarity in the $\mathrm{E} 2$ gene in BCRV isolates over even relatively short 

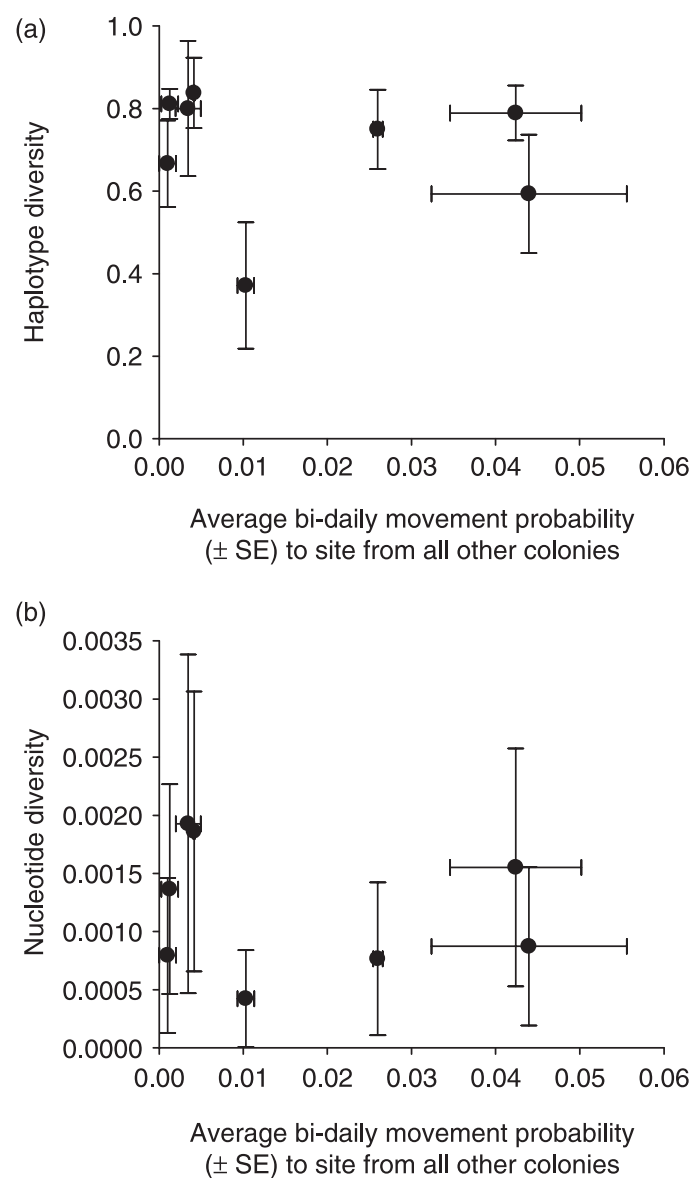

Fig. 4 Lineage B haplotype diversity ( $\pm 1 \mathrm{SE}$ ) (a) and nucleotide diversity ( $\pm 1 \mathrm{SE})(\mathrm{b})$ of the E2 gene in BCRV at a cliff swallow colony site in relation to the bi-daily bird movement probability, $\psi$ ( $\pm 1 \mathrm{SE}$ ), into that site from all others in the study area. Yearly movement probabilities into a site, as reported in Brown et al. (2007), were averaged across years at a site for this analysis. Neither haplotype diversity $\left(r_{\mathrm{s}}=-0.36, P=0.39, n=8\right)$ nor nucleotide diversity $\left(r_{\mathrm{s}}=-0.14, P=0.75, n=8\right)$ varied significantly with movement probability.

distances $(<200 \mathrm{~km})$ is strongly associated with the extent of cliff swallow movement between sites within a summer. To our knowledge, the results are the first for any arbovirus to demonstrate empirically a direct link between virus spatial structure and degree of host/vector movement in space. Although genetic diversity of this virus was also influenced by the distance between sites, distance alone could not explain the correlation between bird movement and $F_{\mathrm{ST}}$ values. Pairwise $F_{\mathrm{ST}}$ was not influenced by overall BCRV prevalence at sites. As more immigrant/transient birds moved into a site, haplotype and nucleotide diversity of BCRV lineage A increased.

We measured cliff swallow movement in this study, because it is far more practical to mark and recapture birds than swallow bugs. However, cliff swallows routinely move bugs (attached to their feet) from site to site (Brown \& Brown 2004a, 2005), so bird movement in our study system in many ways also equates to vector movement. We do not know with certainty to what extent the genetic patterns of the virus reported here reflect infected hosts (cliff swallows) potentially moving virus from site to site, vs. their moving infected bugs from site to site. We suspect, though, that the relationship between virus genetic diversity and bird movement is brought about largely by vector (bug) transport on the birds. Adult and juvenile cliff swallows are very rarely found with viremia (V. O'Brien and C. Brown, unpublished). Bugs, on the other hand, are often infected (Brown et al. 2001; Moore et al. 2007), and at times large numbers disperse from site to site by travelling on the swallows (Brown \& Brown 1996, 2004a, 2005). Thus, cliff swallows that move between sites introduce BCRV and lead to greater genetic homogeneity between sites probably not by moving virus themselves and being fed on by bugs at their destination site, but instead by moving infected bugs from one colony to another.

Bird movement in our study system is often by transient individuals that are not nesting or resident anywhere at the time of their moving (Brown et al. 2007), although they had to be present at colony sites temporarily where they were caught and recaptured. Because transient cliff swallows typically visit multiple colony sites over short time spans and are exposed to large numbers of bugs seeking to disperse from unoccupied nests, transients increase their exposure to bugs and the likelihood of picking up one that has virus (Brown et al. 2007). Consequently, these birds may serve as super-spreaders (sensu Lloyd-Smith et al. 2005) of BCRV, contributing to genetic homogenization of virus among the sites that they visit. The bi-daily movement probabilities between the sites with the greatest genetic similarity (Fig. 2) are very large, especially considering that these are probabilities for a given bird to move during any 2-day interval. This means that these sites experience a relatively high degree of shared transient/nonbreeding cliff swallow traffic. The transient population of cliff swallows in our study area appears to be large (Brown \& Brown 2004a; Brown et al. 2007). Within a season, swallows most often move between colonies that are within $3.5 \mathrm{~km}$ of each other (Brown \& Brown 1996, p. 440), although they have been recorded to move between sites that are up to $59 \mathrm{~km}$ apart during a 3-day interval (Brown et al. 2007).

For lineage A, BCRV isolated in bugs at colony sites with a relatively high degree of bird movement into them showed greater overall haplotype and nucleotide diversity than at sites that attracted fewer transient cliff swallows. Virus is also more prevalent at such sites (Brown et al. 2007). We interpret this to result from the greater likelihood of different haplotypes being introduced to a site as the number of transient birds that carry infected bugs at that site increases. This implies that sites with many haplotypes 
are ones that, for whatever reason(s), are popular with passing birds (Brown et al. 2007) and consequently probably collect many of the virus haplotypes from nearby colonies. Virus strains at these colony sites, overall, may be more representative of the entire population. The effect of bird movement on genetic diversity at a site cannot be attributed to covariation between bird movement and colony size, perhaps with virus at larger colonies simply being more diverse, because bird movement probability is not significantly correlated with colony size (Brown et al. 2007).

Interestingly, for virus lineage B, bird movement had no relationship with either haplotype or nucleotide diversity. This may mean that, despite the similarity between the two lineages in how movement affected pairwise $F_{\mathrm{ST}}$, lineage $\mathrm{B}$ is less likely to be moved by birds (perhaps because it is less likely to be found in dispersing bugs), and therefore lineage $B$ haplotypes do not accumulate at sites with heavy bird traffic. Thus, we would predict lineage A to be more frequently found at newly established swallow colonies that have not had as long for the more gradual colonization by lineage $B$ to occur. There are a number of ecological differences between lineages $\mathrm{A}$ and $\mathrm{B}$, and, consistent with the results reported here, other analyses suggest that lineage $\mathrm{A}$ is more closely associated with birds than is lineage B (C. Brown, A. Padhi, A. Moore, M. Brown, J. Foster, S. Strickler, M. Pfeffer, V. O'Brien, N. Komar, unpublished).

BCRV shows a relatively high degree of spatial structure over small geographical distances. In the pairwise comparisons, some sites had $F_{\mathrm{ST}}$ values of 0.8 or greater, implying extreme differentiation between subpopulations. This runs counter to the widely held view that bird-associated arboviruses are transmitted over wide geographical areas so often that they have reduced genetic diversity as a result, even on a continental scale. Possibly this is because the role of birds in dispersing viruses in general has been overestimated because of the lack of any empirical data (e.g. Dickerman et al. 1980; Anonymous 2006; Olsen et al. 2006). In some ways, the ecology of BCRV is unusual in that migration of virus between sites may be largely via a seemingly sedentary invertebrate vector that nevertheless can be moved long distances by a highly mobile avian host.

Relatively few population-level genetic studies of viruses have been carried out at the spatial scale of our study, and thus, it is difficult to directly compare genetic structure of BCRV to related arboviruses such as EEEV and HJV that are supposedly more genetically uniform over large areas in North America (Cilnis et al. 1996; Weaver et al. 1997). The most closely similar data we are aware of comes from the directly transmitted Zaire strain of Ebola virus (EBOV), in which genetic distance between spatially distinct isolates is directly correlated with pairwise geographical distance between them (Walsh et al. 2005). This EBOV strain appears to spread in a wave-like pattern along rivers (Walsh et al. 2005), and strains or haplotypes of BCRV may also spread in a more or less linear fashion since the bird colony sites are all situated along roads or rivers that run predominantly east-west in our study area (Fig. 1).

In summary, this study indicates that within-season movement of both bird hosts and their associated parasitic vectors in a local area seems to predict genetic diversity and spatial structure of BCRV, at least among isolates taken from the bug vectors. The movement of transient birds that more often encounter virus (or the parasites carrying the virus) contributes to the extreme level of genetic structure characteristic of BCRV (Pfeffer et al. 2006). From this, it would seem that clusters of cliff swallow colonies closely positioned in space (such as in the centre of our study area) would be more likely to contain multiple, similar haplotypes of BCRV, due to heavy swallow traffic among them, than are sites that are more isolated from the next nearest colony and that do not attract many transient birds. Other factors such as distance between sites, presence of invasive house sparrows (V. O'Brien and C. Brown, unpublished), and different evolutionary rates of the two lineages (A. Padhi and C. Brown, unpublished) also likely help generate the spatial structure of this virus. However, our results indicate that bird movement between locations is an empirically measurable and accurate predictor of how genetically similar virus in those areas is likely to be, and that sites with high levels of bird traffic from elsewhere will show greater overall virus diversity, at least for one of the lineages. Our results also suggest caution in interpreting bird movement as always leading to reduced genetic diversity in arboviruses, because in our case, there was a high degree of spatial structure of the virus (at least in the E2 gene) over short distances despite very mobile birds (cliff swallows) clearly moving it within the study area.

\section{Acknowledgements}

We thank S. Aldridge, S. Beckett, J. Blackwell, K. Brazeal, A. Briceno, K. Cornett, E. Edwards, A. Johnson, J. Klaus, E. Landay, J. Leonard, J. Malfait, S. Narotam, V. O'Brien, C. Ormston, N. Panella, S. Quick, S. Robinson, R. Sethi, M. Shanahan, S. Strickler, P. Wallace, and E. Westerman for field and laboratory assistance; K. Winans for help with sequencing; $\mathrm{V}$. O'Brien and two anonymous reviewers for comments on the manuscript; the School of Biological Sciences of the University of Nebraska for use of the Cedar Point Biological Station; and the National Science Foundation (9974733, 0075199, 0514824) and the National Institutes of Health (AI057569) for financial support.

\section{References}

Anonymous (2006) Avian influenza goes global, but don't blame the birds. Lancet Infectious Diseases, 6, 185.

Brault AC, Powers AM, Villarreal CL et al. (1999) Genetic and antigenic diversity among eastern equine encephalitis viruses from North, Central, and South America. American Journal of Tropical Medicine and Hygiene, 61, 579-586. 
Brown CR (1998) Swallow Summer. University of Nebraska Press, Lincoln, Nebraska.

Brown CR, Brown MB (1986) Ectoparasitism as a cost of coloniality in cliff swallows (Hirundo pyrrhonota). Ecology, 67, 1206-1218.

Brown CR, Brown MB (1992) Ectoparasitism as a cause of natal dispersal in cliff swallows. Ecology, 73, 1718-1723.

Brown CR, Brown MB (1995) Cliff swallow (Hirundo pyrrhonota). In: Birds of North America (eds Poole A, Gill F), no. 149. Academy of Natural Sciences, Philadelphia, Pennsylvania, and the American Ornithologists' Union, Washington, D.C.

Brown CR, Brown MB (1996) Coloniality in the Cliff Swallow: The Effect of Group Size on Social Behavior. University of Chicago Press, Chicago, Illinois.

Brown CR, Brown MB (2004a) Empirical measurement of parasite transmission between groups in a colonial bird. Ecology, 85, 1619-1626.

Brown CR, Brown MB (2004b) Group size and ectoparasitism affect daily survival probability in a colonial bird. Behavioral Ecology and Sociobiology, 56, 498-511.

Brown CR, Brown MB (2005) Between-group transmission dynamics of the swallow bug, Oeciacus vicarius. Journal of Vector Ecology, 30, 137-143.

Brown CR, Komar N, Quick SB et al. (2001) Arbovirus infection increases with group size. Proceedings of the Royal Society B: Biological Sciences, 268, 1833-1840.

Brown CR, Brown MB, Moore AT, Komar N (2007) Bird movement predicts Buggy Creek virus infection in insect vectors. Vector-Borne and Zoonotic Diseases, 7, 304-314.

Burnham KP, Anderson DR (2002) Model Selection and Multimodel Inference: A Practical Information-Theoretic Approach, 2nd edn. Springer, New York.

Calisher CH, Maness KSC, Lord RD, Coleman PH (1971) Identification of two South American strains of eastern equine encephalomyelitis virus from migrant birds captured on the Mississippi delta. American Journal of Epidemiology, 94, 172178.

Calisher CH, Monath TP, Muth DJ et al. (1980) Characterization of Fort Morgan virus, an alphavirus of the western equine encephalitis virus complex in an unusual ecosystem. American Journal of Tropical Medicine and Hygiene, 29, 1428-1440.

Calisher CH, Karabatsos N, Lazuick JS, Monath TP, Wolff KL (1988) Reevaluation of the western equine encephalitis antigenic complex of alphaviruses (family Togaviridae) as determined by neutralization tests. American Journal of Tropical Medicine and Hygiene, 38, 447-452.

Carrington CVF, Foster JE, Pybus OG, Bennett SN, Holmes EC (2005) Invasion and maintenance of dengue virus type 2 and type 4 in the Americas. Journal of Virology, 79, 14680-14687.

Chapman BR, George JE (1991) The effects of ectoparasites on cliff swallow growth and survival. In: Bird-Parasite Interactions: Ecology, Evolution and Behaviour (eds Loye JE, Zuk M), pp. 69-92. Oxford University Press, Oxford, UK.

Cilnis MJ, Kang W, Weaver SC (1996) Genetic conservation of Highlands J viruses. Virology, 218, 343-351.

Crans WJ, Caccamise DF, McNelly JR (1994) Eastern equine encephalomyelitis virus in relation to the avian community of a coastal cedar swamp. Journal of Medical Entomology, 31, 711-728.

Dickerman RW, Martin MS, Dipaola EA (1980) Studies of Venezuelan encephalitis in migrating birds in relation to possible transport of virus from South to Central America. American Journal of Tropical Medicine and Hygiene, 29, 269-276.
Domingo E (1998) Quasispecies and the implications for virus persistence and escape. Clinical and Diagnostic Virology, 10, 97101.

Gould EA, de Lamballerie X, Zanotto PMA, Holmes EC (2001) Evolution, epidemiology, and dispersal of flaviviruses revealed by molecular phylogenies. Advances in Virus Research, 57, 71103.

Hayes RO, Francy DB, Lazuick JS, Smith GC, Gibbs EPJ (1977) Role of the cliff swallow bug (Oeciacus vicarius) in the natural cycle of a western equine encephalitis-related alphavirus. Journal of Medical Entomology, 14, 257-262.

Hopla CE, Francy DB, Calisher CH, Lazuick JS (1993) Relationship of cliff swallows, ectoparasites, and an alphavirus in west-central Oklahoma. Journal of Medical Entomology, 30, 267-272.

Lebreton JD, Pradel R (2002) Multistate recapture models: modeling incomplete individual histories. Journal of Applied Statistics, 29, 353-369.

Lindsay MDA, Coelen RJ, Mackenzie JS (1993) Genetic heterogeneity among isolates of Ross River virus from different geographical regions. Journal of Virology, 67, 3576-3585.

Lloyd-Smith JO, Schreiber SJ, Kopp PE, Getz WM (2005) Superspreading and the effect of individual variation on disease emergence. Nature, 438, 355-359.

Lord RD, Calisher CH (1970) Further evidence of southward transport of arboviruses by migratory birds. American Journal of Epidemiology, 92, 73-78.

Loye JE (1985) The life history and ecology of the cliff swallow bug, Oeciacus vicarius (Hemiptera: Cimicidae). Cahiers Office de la Recherche Scientifique et Technique Outre-Mer, Serie Entomologie Medicale et Parasitologie, 23, 133-139.

Loye JE, Carroll SP (1991) Nest ectoparasite abundance and cliff swallow colony site selection, nestling development, and departure time. In: Bird-Parasite Interactions: Ecology, Evolution and Behaviour (eds Loye JE, Zuk M), pp. 222-241. Oxford University Press, Oxford, UK.

Merrill SA, Ramberg FB, Hagedorn HH (2005) Phylogeography and population structure of Aedes aegypti in Arizona. American Journal of Tropical Medicine and Hygiene, 72, 304-310.

Moore AT, Edwards EA, Brown MB, Komar N, Brown CR (2007) Ecological correlates of Buggy Creek virus infection in Oeciacus vicarius, southwestern Nebraska, 2004. Journal of Medical Entomology, 44, 42-49.

Myers LE (1928) The American swallow bug, Oeciacus vicarius Horvath (Hemiptera, Cimicidae). Parasitology, 20, 159-172.

Navaratnarajah CK, Kuhn RJ (2007) Functional characterization of the Sindbis virus E2 glycoprotein by transposon linker-insertion mutagenesis. Virology, 363, 134-147.

Nichols JD, Kendall WL (1995) The use of multi-state capturerecapture models to address questions in evolutionary ecology. Journal of Applied Statistics, 22, 835-846.

Norder H, Lundström JO, Kozuch O, Magnius LO (1996) Genetic relatedness of Sindbis virus strains from Europe, the Middle East, and Africa. Virology, 222, 440-445.

Olsen B, Munster VJ, Wallensten A, Waldenström J, Osterhaus ADM, Fouchier RAM (2006) Global patterns of influenza A virus in wild birds. Science, 312, 384-388.

Pfeffer M, Foster JE, Edwards EA, Brown MB, Komar N, Brown CR (2006) Phylogenetic analysis of Buggy Creek virus: evidence for multiple clades in the western Great Plains, United States of America. Applied and Environmental Microbiology, 72, 68866893. 
Poidinger M, Roy S, Hall RA et al. (1997) Genetic stability among temporally and geographically diverse isolates of Barmah Forest virus. American Journal of Tropical Medicine and Hygiene, 57, 230-234.

Posada D (2004) COLLAPSE: Describing Haplotypes from Sequence Alignments, Version 1.2. University of Vigo, Vigo, Spain.

Powers AM, Brault AC, Shirako Y, Strauss EG, Kang W, Strauss JH, Weaver SC (2001) Evolutionary relationships and systematics of the alphaviruses. Journal of Virology, 75, 10118-10131.

Pradel R, Hines JE, Lebreton J-D, Nichols JD (1997) Capture-recapture survival models taking account of transients. Biometrics, 53, $60-72$.

Pradel R, Gimenez O, Lebreton J-D (2005) Principles and interest of GOF tests for multistate capture-recapture models. Animal Biodiversity and Conservation, 28, 189-204.

Rannala BH (1995) Demography and genetic structure in island populations. PhD Thesis, Yale University, New Haven, Connecticut.

Rappole JH, Hubálek Z (2003) Migratory birds and West Nile virus. Journal of Applied Microbiology, 94, 47S-58S.

Reed KD, Meece JK, Henkel JS, Shukla SK (2003) Birds, migration and emerging zoonoses: West Nile virus, Lyme disease, influenza A and enteropathogens. Clinical Medicine E Research, 1,5-12.

Sammels LM, Lindsay MD, Poidinger M, Coelen RJ, Mackenzie JS (1999) Geographic distribution and evolution of Sindbis virus in Australia. Journal of General Virology, 80, 739-748.

Schneider S, Roessli D, Excoffier L (2000) ARLEQUIN: A Software for Population Genetics Data Analysis, Version 3.1. Genetics and Biometry Laboratory, University of Geneva, Geneva, Switzerland.

Scott TW, Bowen GS, Monath TP (1984) A field study on the effects of Fort Morgan virus, an arbovirus transmitted by swallow bugs, on the reproductive success of cliff swallows and symbiotic house sparrows in Morgan County, Colorado, 1976. American Journal of Tropical Medicine and Hygiene, 33, 981-991.

Sellers RF (1989) Eastern equine encephalitis in Quebec and Connecticut, 1972: introduction by infected mosquitoes on the wind? Canadian Journal of Veterinary Research, 53, 76-79.

Smith GC, Eads RB (1978) Field observations on the cliff swallow, Petrochelidon pyrrhonota (Vieillot), and the swallow bug, Oeciacus vicarius Horvath. Journal of the Washington Academy of Sciences, $68,23-26$.

Strauss JH, Strauss EG (1994) The alphaviruses: gene expression, replication, and evolution. Microbiological Reviews, 58, 491562.

Tabachnick WJ (1992) Microgeographic and temporal genetic variation in populations of the bluetongue virus vector Culicoides variipennis (Diptera: Ceratopogonidae). Journal of Medical Entomology, 29, 384-394.

Traore O, Sorho F, Pinel A et al. (2005) Processes of diversification and dispersion of rice yellow mottle virus inferred from large-scale and high-resolution phylogeographical studies. Molecular Ecology, 14, 2097-2110.

Usinger RL (1966) Monograph of Cimicidae. Thomas Say Foundation, College Park, Maryland.

Walsh PD, Biek R, Real LA (2005) Wave-like spread of Ebola Zaire. PLoS Biology, 3, 1946-1953.

Weaver SC, Bellew LA, Gousset L, Repik PM, Scott TW, Holland JJ (1993) Diversity within natural populations of eastern equine encephalomyelitis virus. Virology, 195, 700-709.

Weaver SC, Hagenbaugh A, Bellew LA et al. (1994) Evolution of alphaviruses in the eastern equine encephalomyelitis complex. Journal of Virology, 68, 158-169.

Weaver SC, Kang W, Shirako Y, Rumenapf T, Strauss EG, Strauss JH (1997) Recombinational history and molecular evolution of western equine encephalomyelitis complex alphaviruses. Journal of Virology, 71, 613-623.

Weaver SC, Ferro C, Barrera R, Boshell J, Navarro J-C (2004) Venezuelan equine encephalitis. Annual Review of Entomology, 49, 141-174.

White GC, Burnham KP (1999) Program MARK: survival estimation from populations of marked animals. Bird Study, 46, S120-S139.

Zanotto PMA, Gao GF, Gritsun T et al. (1995) An arbovirus cline across the Northern Hemisphere. Virology, 210, 152-159.

Charles R. Brown is a behavioral ecologist interested in the effects of arboviruses (especially Buggy Creek virus) on birds, and he has studied cliff swallows for the past 26 years. Mary Bomberger Brown is a conservation biologist who has also done long-term work on cliff swallows and is currently studying endangered least terns and piping plovers. Abinash Padhi is an evolutionary biologist with interests in phylogenetics, working with both catfish and viruses. Jerome E. Foster is a virus phylogeneticist, with interests in dengue virus. Amy T. Moore works exclusively on the ecology and evolution of Buggy Creek virus. Martin Pfeffer is a microbiologist interested in the molecular biology and evolution of alphaviruses. Nicholas Komar studies the relationships between birds and their arboviruses and especially the role of birds in virus transmission cycles. 